\title{
Quasi-simultaneous Measurements of Suspended Sediments Concentration (SSC) of Very Turbid Waters at the Yellow River Estuary with the Multi-spectral HJ-1 Imageries and In-situ Sampling
}

\author{
Qianguo Xing *a ${ }^{\mathrm{a}}$, Mingjing Lou ${ }^{\mathrm{a}}$, Liqiao Tian ${ }^{\mathrm{b}}$, Dingfeng $\mathrm{Yu}^{\mathrm{c}}$, Federica Braga ${ }^{\mathrm{d}}$, Luigi Tosi ${ }^{\mathrm{d}}$, Lingling \\ $\mathrm{Wu}^{\mathrm{a}}$ \\ ${ }^{a}$ Yantai Institute of Coastal Zone Research, Chinese Academy of Sciences, Yantai, China 264003; \\ ${ }^{\mathrm{b}}$ Wuhan University, Wuhan, China 430072; ${ }^{\mathrm{c}}$ Institute of Oceanographic Instrumentation, Shandong

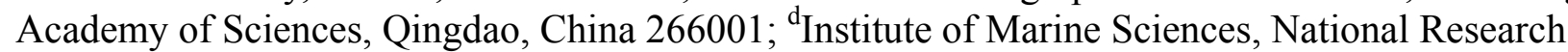 \\ Council, Venezia, Italy \\ * qgxing@yic.ac.cn
}

\begin{abstract}
Evolution of river delta is highly related to the deposition and re-suspension of sediments. At the interacting zone between fresh water of river discharge and seawater, suspended sediments concentration (SSC) varies sharply from a few $\mathrm{mg} / \mathrm{L}$ to thousands of $\mathrm{mg} / \mathrm{L}$; thus, mapping the distribution of SSC will provide the basic information about sediments transportation. The high spatial resolution $(30 \mathrm{~m})$ and high revisit frequency $(2$ day $)$ of CCD imager on board the Chinese environment-monitoring satellite constellation: HJ-1A and HJ-1B, enable an effective observation of the fine dynamics of suspended sediments. In this work, three intensive cruises in the flooding season and dry season of Yellow River were carried out to explore the SSC retrieval algorithms on the basis of HJ-1 CCD imageries. Quasi-simultaneous in-situ SSC data were collected with the pass of HJ-1 over the Yellow River Estuary and its vicinity waters, and a local empirical retrieval algorithm of SSC was established against the TOA (top of atmosphere) reflectance of HJ-1 CCD bands with the correction of Rayleigh scattering. This algorithm can be applied to very turbid waters with thousands of $\mathrm{mg} / \mathrm{L}$ of SSC.
\end{abstract}

Keywords: Suspended Sediments Concentration, turbid waters, HJ-1 CCD, the Yellow River Estuary, the Bohai Sea

\section{INTRODUCTION}

Estuarine waters are often characterized by high concentrations of suspended sediments concentration (SSC) due to sediment resuspension and terrestrial inputs from the large rivers. SSC in coastal waters exhibits high dynamics with high concentrations that can vary sharply from a few $\mathrm{mg} / \mathrm{L}$ to thousands of $\mathrm{mg} / \mathrm{L}$, which impacts the light distribution, the benthic ecosystem and the productivity of upper-layer phytoplankton. It is a fundamental work of knowing the distributions of SSC for exploring the sediments transportation. Thus, monitoring the dynamics of SSC is of importance. The high spatio-temporal variability, however, makes it difficult to quickly estimate SSC in estuarine waters by traditional field investigating methods. With the development in remote sensing techniques, using satellite imagery to monitor the water quality has been widely used and has become a popular topic in the field of coastal oceanography ${ }^{[1]}$.

Over the past decades, satellite ocean color data have been used to estimate the SSC in various coastal regions ${ }^{[2]}$, along with sensors like the Sea-viewing Wide Field-of-view Sensor (SeaWiFS), the Moderate Resolution Imaging Spectroradiometer (MODIS), and the Medium Resolution Imaging Spectrometer (MERIS). Meanwhile, landobservation-oriented sensors such as the Landsat series and Advanced Land Imager (ALI) have also been employed to assess the SSC. However, the low spatial resolution of ocean color sensors (e.g., the highest spatial resolution of MODIS is only $250 \mathrm{~m}$ ) and the long revisit time of land-observation-oriented sensors (e.g., the revisit cycle of Landsat TM is 16 days) are still far below the demand for monitoring sediments variation in dynamic water bodies. The "environment and disaster monitoring and forecasting small satellite constellations" (HJ-1A/1B satellites), launched by China on September 6, 2008, are equipped with two charge-coupled device (CCD) cameras with both mid-high spatial resolution and short revisit time (2 days). CCDs on both HJ-1A and HJ-1B satellite have 4 bands at visible and near infrared region

Ocean Remote Sensing and Monitoring from Space, edited by Robert J. Frouin, Delu Pan,

Hiroshi Murakami, Young Baek Son, Proc. of SPIE Vol. 9261, 92610S · @ 2014 SPIE

CCC code: $0277-786 \mathrm{X} / 14 / \$ 18 \cdot$ doi: $10.1117 / 12.2068930$

Proc. of SPIE Vol. 926192610 S-1 
(Band 1: 430-520 nm, Band 2: 520-600 nm, Band3: 630-690 nm, Band 4: 760-900 nm). Its nadir pixel resolution is about $30 \mathrm{~m}$, and the view width is $360 \mathrm{~km}$. The data collection time of this area is about 10:30 AM (local time). The HJ1A/1B CCD may be a suitable tool to rapid and simultaneous assessment of SSC in estuarine waters.

In this study, we take the Yellow River Estuary as the field testing site. The Yellow River is the second largest river in China; it flows through Qinghai, Ningxia, Shanxi, Henan, the largest loess deposit area in the world, and finally enters into the Bohai Sea. Sediment discharge from the Yellow River to the sea is one of the world's largest input, which also makes the Yellow River become one of the most dominant land-based effects on the ecosystem of the Bohai Sea. The freshwater input and suspended sediments have not only sustained the morphology but also nourished the coastal zone because of large amount of nutrients released from the river. Understanding the tranport and deposition of suspended sediments is important for the assessment of coastal evolution. This work was conducted to develop regional SSC algorithms to map SSC using HJ-1A/HJ-1B CCD data in turbid estuarine waters and then give a presentation of seasonal distribution of SSC in the Yellow River Estuary.

\section{DATA \& METHDOS}

Five HJ-1 CCD Level 2 images were acquired at the Yellow River Estuary in the Bohai Bay on 24-April-2013, 15-Aug2013, 07-Sep-2013, 27-Oct-2013 and 30-Dec-2013, respectively. The field investigations were carried out on 15-Oct2013 and 07-Sep-2013, with which the SSC of the Yellow River Estuary was measured.

First of all, satellite images were preprocessed and atmospheric corrected to ground surface reflectance. Signal from molecule scattering and aerosol scattering strongly impacts ocean satellite observation, and the impacts need to be corrected. Two atmospheric correction methods, rayleigh scattering correction (RSC) and fast line-of-sight atmospheric analysis of spectral hypercubes (FLAASH), which have good performance in turbid water situation ${ }^{[3]}$, were used to retrieve the ground reflectance, $R_{r c}$ and $R_{F L A S H}$ (unitless).

In this work, HJ-1 CCD data were first correct by removing molecular scattering.

$$
R_{r c}=\pi L_{t}^{*} /\left(F_{0} \cos \theta_{0}\right)-R_{r}
$$

where $L_{t}^{*}$ is the calibrated sensor radiance after adjustment for ozone and other gaseous absorption, $F_{0}$ is the extraterrestrial solar irradiance, $\theta_{0}$ is the solar zenith angle at data acquisition time, and $R_{r}$ is the Rayleigh reflectance estimated with $6 \mathrm{~S}^{[4]}$.

Further, FLAASH model was applied in order to wipe off the aerosol effect. And the aerosol model was set as maritime experientially.

$$
L=\left(\frac{\mathrm{A} R_{F L A A S H}}{1-R_{\mathrm{e}}}\right)+\left(\frac{\mathrm{B} R_{e}}{1-R_{\mathrm{e}} S}\right)+L_{a}
$$

Where $L$ is the radiance from the surface and travels directly into the sensor, $R_{F L A A S H}$ is the pixel surface reflectance, $R_{\mathrm{e}}$ is an average surface reflectance for the pixel and its surrounding region, $\mathrm{S}$ is the spherical albedo of the atmosphere,

$L_{a}$ is the radiance scattered by the atmosphere, A and B are cofficients that depend on atmospheric and geometric conditions. A, B and $L_{a}$ are estimated from MODTRAN4.

Single-band and multi-band algorithms (e.g., band ratios) have been used in previous studies ${ }^{[5-7]}$. Several band combinations of $R_{r c}, R_{r c 830}, R_{r c 830} / R_{r c 500}$ and $R_{r c 830} / R_{r c 600}$ (Fig.2) were tested to achieve the best SSC retrieval performance by polynomial, exponential and power fitting. $R_{F L A A S H}$ are alternative parameters for retrieving SSC. In this study, correlation between $R_{F L A A S H}$ and $R_{r c}$ of the entire image was first calculated, then $R_{F L A A S H}$ was transformed into $R_{r c}$ on the basis of the significant correlations, and applied into the SSC retrieval.

Finally, SSC of all seasons, 24-April-2013, 15-Aug-2013, 27-Oct-2013 and 30-Dec-2013 were estimated using $R_{F L A S H}$. 


\section{RESULTS \& DISCUSSION}

Red and infrared reflectance bands of water are usually sensitive to high SCC ${ }^{[6,7]}$. Our study shows the similar results. As shown in Fig.1, band 3 and band 4 have higher correlation with SCC than band 1 and band 2. As shown in Fig. 3, the single band or band ratios have good correlations $\left(\mathrm{R}^{2}>0.96\right)$ with SSC which were quasi-simultaneously sampled and measured with the overpass of HJ-1. The retrieval algorithm based on the polynomial regression of band 4 with SSC has the best performance, $R^{2}, 0.96$ (Fig.2a, Fig.3).

Good linear correlations are observed between $R_{F L A A S H}$ and $R_{r c}$ of band 4 (r>0.98) (Fig.4), which makes it possible to estimate SSC using $R_{F L A S H}$. The regression equation derived on 15-Aug-2013 (r=0.99), was adopted to convert $R_{F L A A S H}$ into $R_{r c}$ in case of the absence of RSC. Please note, the lower correlation for the image of 24-April-2013 was caused by larger errors in the geometric matching between $R_{F L A A S H}$ and $R_{r c}$.

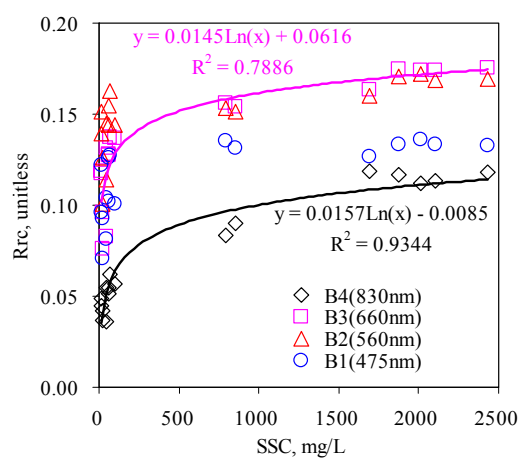

Fig.1 SSC vs. HJ-1 bands
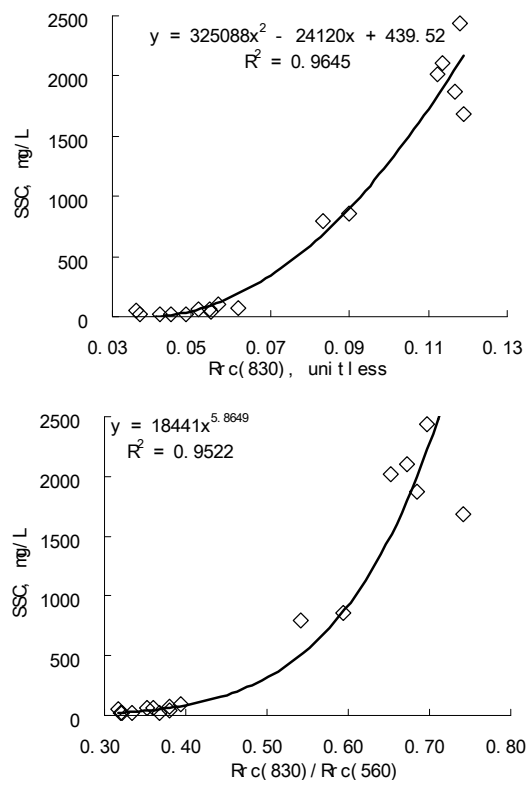

(a)

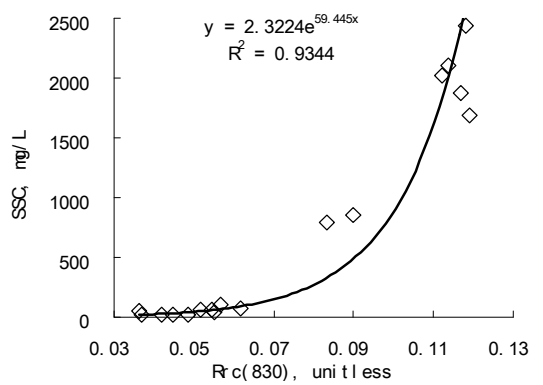

(b)

Fig.2 Algorithms for estimating SSC with $\mathrm{R}_{\mathrm{rc}}$

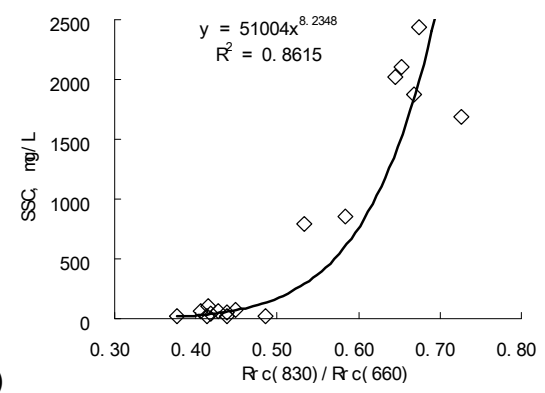

(d) 


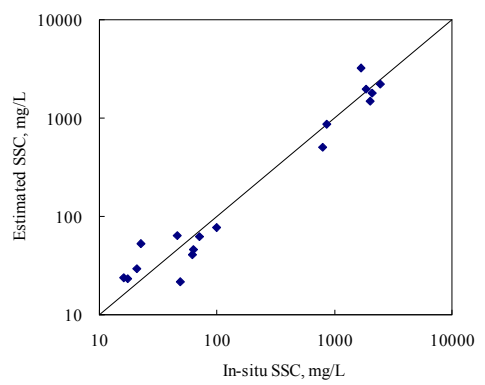

Fig.3 Retrieved SSC from HJ-1 data and measured SSC from field work
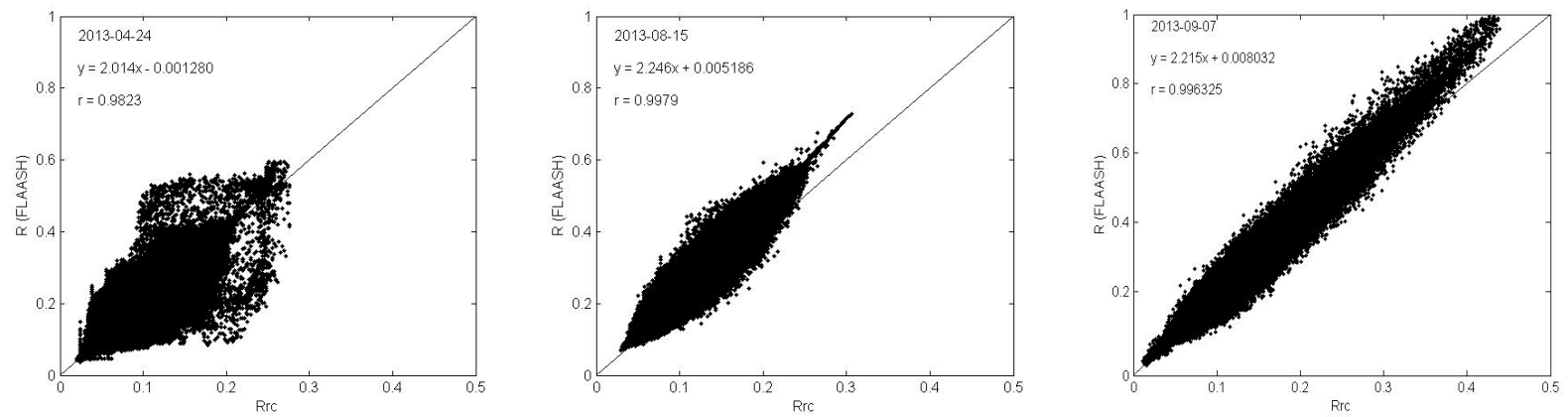

Fig.4 Scatter plot of R(FLAASH) vs. Rrc

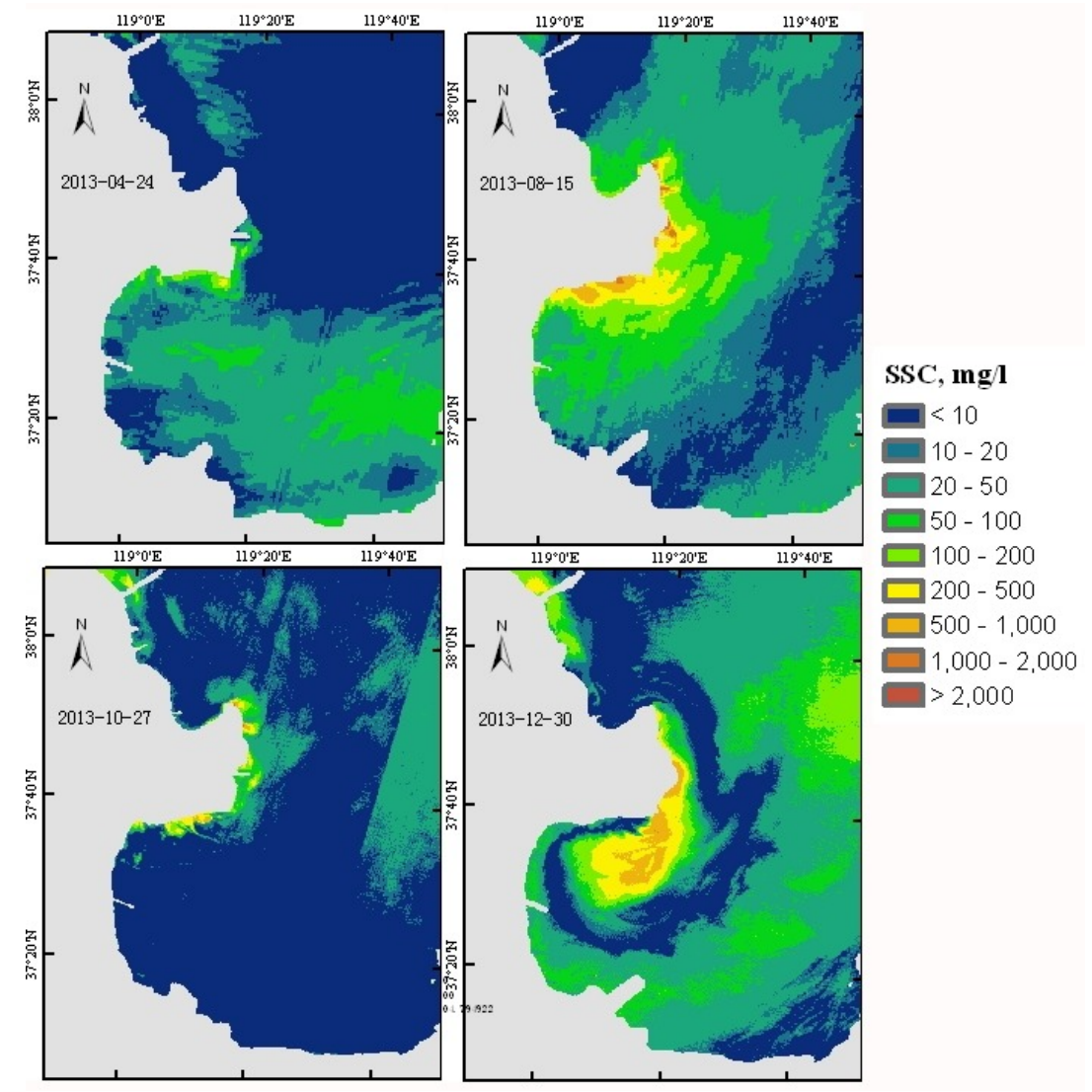

Fig.5 SSC distribution in different seasons 
Fig. 5 shows the distribution of SSC in the Yellow River and Laizhou Bay from spring to winter. SSC is extraordinarily high in wet season (August) as much as $2000 \mathrm{mg} / \mathrm{L}$ which is due to the Yellow River sediments input. In spring (April) and autumn (October), the SSC is low due to lower sediments input and lower wind-driven turbulence. SSC in winter turns out to be particularly high in a vast region in the Bohai Sea; especially in the north of Yellow River Delta and the north part of the Laizhou Bay, SSC in the offshore shallow area is higher than $200 \mathrm{mg} / \mathrm{l}$ despite the low concentration in the Yellow River. This situation in winter is highly correlated the wind stress and vertical mixing. What's more, there is an all year around low SSC area to the north of Yellow River estuary, which is likely due to the protection of the manmade bank and lower velocity of tidal current. It is reported that there is an amphidromic point which may keep the sediment of Yellow River discharge out of this region ${ }^{[8]}$.

\section{SUMMARY}

In this study, field investigations were carried out to measure the SSC in the Yellow River estuary with the over-fly of Chinese environment-monitoring satellite HJ-1. Regression models were established to retrieve SSC in the Yellow River estuary and its vicinity waters. HJ-1 images in four seasons were collected to retrieve SSC in this region, and they show different distribution patterns of SSC which are related to local circulations, wind and river runoff patterns. This work demonstrates that it is feasible to estimate SSC of very turbid coastal waters using HJ-1 CCD data.

\section{ACKNOWLEDGEMENTS}

This work was supported by the CAS/SAFEA International Partnership Program for Creative Research Teams "Representative environmental processes and resources effects in coastal zone". HJ-1 satellite data is provided under the framework of ESA-NCSCC dragon-III program (ID: 10558).

\section{REFERENCES}

[1] Zhang, M., Tang, J., Dong, Q., Song, Q. and Ding, J., "Retrieval of total suspended matter concentration in the Yellow and East China Seas from MODIS imagery," Remote Sensing of Environment, Papers 114(2), 392-403 (2010).

[2] Tassan, S., "Local algorithms using SeaWiFS data for the retrieval of phytoplankton, pigments, suspended sediment, and yellow substance in coastal waters," Applied Optics, Papers 33(12), 2369-2378 (1994).

[3] Zeng, Q., Zhao, Y., Tian, L., and Chen, X., "Evaluation on the atmospheric correction methods for water color remote sensing by using HJ-1A/1B CCD image-taking Poyang Lake in China as a case," Spectroscopy and Spectral Analysis, Papers 33(5), 1320-1326 (2013).

[4] Vermote, E. F., Tanre, D., Deuze, J. L., Herman, M., and Morcette, J. J., $\quad$ "Second simulation of the satellite signal in the solar spectrum, 6S: An overview," IEEE Transactions on Geoscience and Remote sensing, Papers 35(3), 675-686 (1997).

[5] Xing, Q., Lou, M., Chen, C., and Shi, P., "Using in situ and Satellite hyperspectral data to estimate the surface suspended sediments concentrations in the Pearl River Estuary," IEEE Journal of Selected Topics in Applied Earth Observations and Remote Sensing, Papers 6 (2), 731-738 (2013).

[6] Doxaran, D., Froidefond, J. M., Lavender, S., and Castaing, P., "Spectral signature of highly turbid waters: Application with SPOT data to quantify suspended particulate matter concentrations," Remote Sensing of Environment, Papers 81, 149-161 (2002).

[7] Ma, W., Xing, Q., Chen, C., Zhang, Y., Yu, D., and Shi P., "Using normalized peak area of remote sensing reflectance in the near-infrared region to estimate total suspended matter," International Journal of Remote Sensing, Papers 32 (22), 7479-7486 (2011).

[8] Wen, L., Zhang, J., "Analysis of the sediment transport of Huanghe River Estuary and the distribution of suspended sediment in Bohai Bay by using remote sensing technology," Journal of Waterway and Harbor, Papers 3, 33-37 (1989). 